\title{
Disinfecting gingival crevices by Non-thermal atmospheric pressure plasma
}

\author{
Sun $\mathrm{SY}^{2 *}$, Ji H ${ }^{2 *}$, Hsu JT ${ }^{1}$ and Wang $\mathrm{MC}^{2 *}$ \\ ${ }^{1}$ Department of Dentistry, China Medical University, Taiwan \\ ${ }^{2}$ Department of Biomedical Engineering, Chung Yuan Christian University, Taiwan
}

\begin{abstract}
Recently, dental visits have gradually increased. According to the statistical data of the Taiwan Food and Drug Administration (TFDA) in 2014, the dental disease visits have reached 35 million. Now, we use toothbrushes and mouthwash to remove dental plaque, to keep periodontal diseases away. Non-thermal Atmospheric Pressure Plasma as an application of the bactericidal method is used in the biomedical field. In this study, we designed a brace plasma reactor, and examined bactericidal effects. The results show that our plasma system can achieve $90 \%$ inactivation ( $D$-value) by $120 \mathrm{~s}$, when the peak-to-peak voltage, the frequency of the applied voltage, and the input power were $2.52 \mathrm{kV}_{\mathrm{p} \text {-p }}, 5.092 \mathrm{kHz}$, and $1.227 \mathrm{~W}$. In addition, the surface temperature of the reactor is below $50^{\circ} \mathrm{C}$ in the $D$-value, so the plasma reactor is suitable for oral cavity of human.
\end{abstract}

\section{Introduction}

Periodontal disease that is caused by oral biofilms, which are the co-aggregation of bacteria, can lead to the destruction of periodontium. Subgingival biofilms have the capacity to trigger a series of inflammatory responses, which can destroy the gingival cells and the alveolar bone. If it becomes exacerbated, the result is tooth loss [1]. According to the statistical data of the TFDA in 2014, the number of people seeking dental advice has reached 35 million.

Now, we use toothbrushes and mouthwash to remove dental plaque, to keep periodontal diseases away. Whichever we choose, bacteria still remain in the gingival crevices. In the field of nonsurgical treatment, the conventional mechanical treatment can eradicate microbes by scaling and root planing [2]. One of nonsurgical treatments is antimicrobial photodynamic therapy (aPDT). The principle of aPDT is to match suitable wavelength light with photosensitizer to produce singlet oxygen and other reactive species, the poisonous substances to bacteria $[3,4]$. The device uisng aPDT requires a LED or laser source to activate the photosensitizers. In this study we introduce an alternatve device which is simple and low cost. Recent research shows that in the biomedical field plasma is effective in disinfecting the ambient air at room temperature. Plasma, a state which is ionized gas, contain a lot of species due to many reaction as shown in table. 1, including ionization, excitation, recombination, dissociation, charge exchange, elastic scattering, chemical reaction. The antimicrobial effect are attributed to the oxidation stress of reactive oxygen species (ROS), as Figure 1, that are generated by plasma, including ozone, $\mathrm{OH}$ and hydrogen peroxide etc.

In this study, to keep periodontal disease away and to improve the used way, we designed a brace plasma reactor, and examined bactericidal effects. In addition, we detected the components of plasma species by Optical emissions spectroscopy (OES), measuring the input of power. Finally, we measured the temperature of the reactor surface to determine whether the inactivation is thermal-dependent, and it is suitable for the human oral cavity.

\section{Materials and methods}

\section{Plasma instrument}

Figures 2 and 3 illustrate the Non-thermal Atmospheric Pressure Plasma System which contains the power generator and reactor used in this study. Covered by epoxy that serves as an insulating layer, copper electrodes $(0.3 \mathrm{~mm}$ wide, distance of each electrode is $0.3 \mathrm{~mm})$ were used as an inverse sinuous high-voltage. Charge would be accumulated on PCB plate which serves as a dielectric layer. Figure 4 shows the self-designed input power generator.

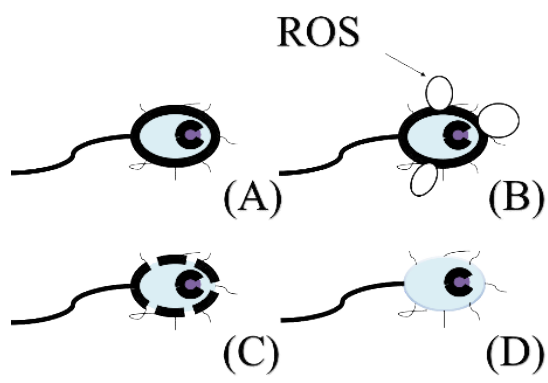

Figure 1. The bactericidal principle of ROS. (A) a normal bacterium. (B) the ROS attach to bacterium. (C) The cell membrane of bacterium was affected by ROS, forming Volatile substance. (D) the bacterium died by cell membrane cleavage.

Correspondence to: Wang MC, Graduate Student, Department of Dentistry, China Medical University, Taiwan, Tel: + 88632654524; E-mail: samwang@cycu.edu.tw

Key words: Periodontal diseases, non-thermal plasma, ROS, E. coli

Received: August 14, 2016; Accepted: September 02, 2016; Published: September 05, 2016 


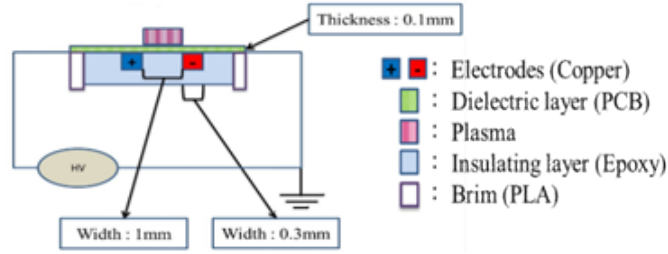

Figure 2. Schematic illustration of the Non-thermal Atmospheric Dielectric Barrier Discharge (DBD) system.

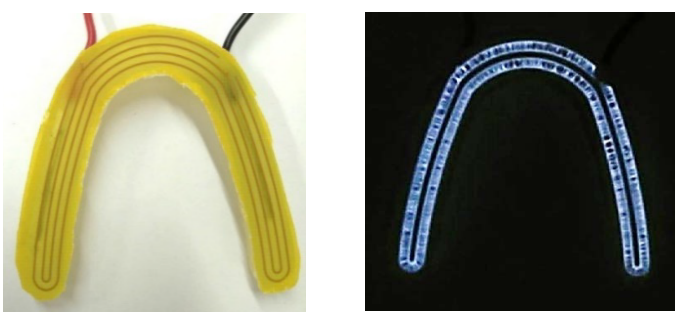

Figure 3. Schematic illustration of the Non-thermal Atmospheric Dielectric Barrier Discharge (DBD) system.
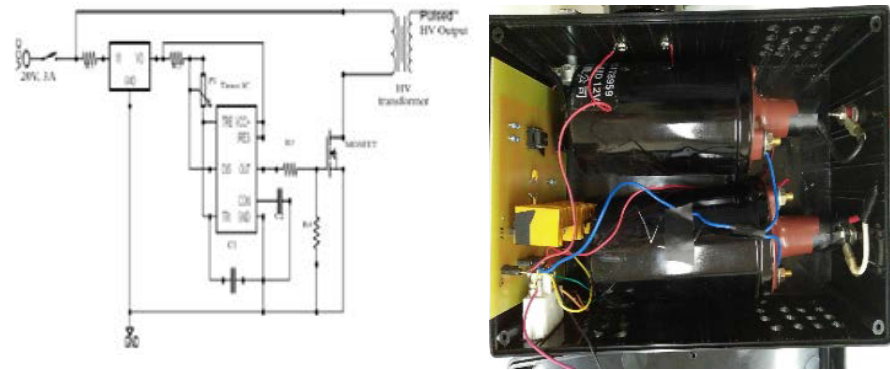

Figure 4. Power generator. (A) self design circuit; (B) real photograph.
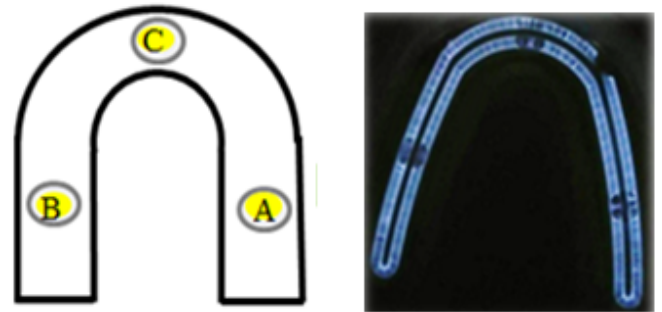

Figure 5. The treatment position.

\section{Bactericidal test}

For this antimicrobial experiment, E. coli (ATCC 25922) was used, which is a Gram- negative bacterium that would result in dental caries after being cultured for $12 \mathrm{hr}$. Bacteria were grown in a lysogeny broth (LB) medium to $\mathrm{OD}_{600}=0.08 \pm 0.02$, corresponding to approximately $10^{7}$ colony-forming units per $\mathrm{ml}(\mathrm{CFU} / \mathrm{ml}) .5 \mu \mathrm{l}$ of bacterial solution were dropped onto coverslips (diameter is $5 \mathrm{~mm}$ ) which were placed on the reactor surface randomly as shown in Figure 5. Briefly, there are approximately $5 \times 10^{5} \mathrm{CFU}$ bacteria on the coverslips. After the bacterial solution was run dry, colonies of coverslips of the experimental group were placed on the reactor surface randomly, treated in close system, gathered by sonication bacteria that attached to coverslips and cultured $10 \mu \mathrm{l}$ of bacteria solution on LB agar in $37^{\circ} \mathrm{C}$ for $8 \mathrm{hr}$. Finally, colonies were counted to determine the number on LB agar. Colonies of coverslip of the control group were gathered in the same way as described for the experimental group.
The antibacterial effect of each treatment was determined by calculating the $\log$ reduction, $\log \left(N_{0} / N\right)$, where $N_{0}$ is the number of coverslip cells present in an untreated sample and $N$ is the number of coverslips cells present in a treated sample.

\section{Results and discussion}

To apply on the oral of human, the temperature of this plasma reactor surface must keep on $40 \pm 5^{\circ} \mathrm{C}$. When the input parameters are $2.52 \mathrm{kVp}-\mathrm{p}, 5.092 \mathrm{kHz}$, and $1.227 \mathrm{~W}$, the temperature of this plasma reactor surface within $43.3^{\circ} \mathrm{C}$. Under this condition, the maximum intensity of lights of $777.32 \mathrm{~nm}$ and $845.74 \mathrm{~nm}$, major inactivating species, are detected by OES.

Effects of plasma on microorganisms: As shown in Figure 6 , there are no obvious differences in bactericidal effects between the three randomly selected points. The decimal reduction time for inactivating $90 \%$ of the microbial population is achieved by $120 \mathrm{~s}$, and E. coli was completely inactivated in $4 \mathrm{~min}$.

Optical Emissions Spectroscopy examination: As shown in Figure 7 and Figure 8, multitude species are observed when working parameters were $\mathrm{V}_{\mathrm{p}-\mathrm{p}}=2.52 \mathrm{kV}, \mathrm{f}=5.092 \mathrm{kHz}$ and $\mathrm{P}=1.227 \mathrm{~W}$.

Spectra of $\mathrm{N}_{2}$

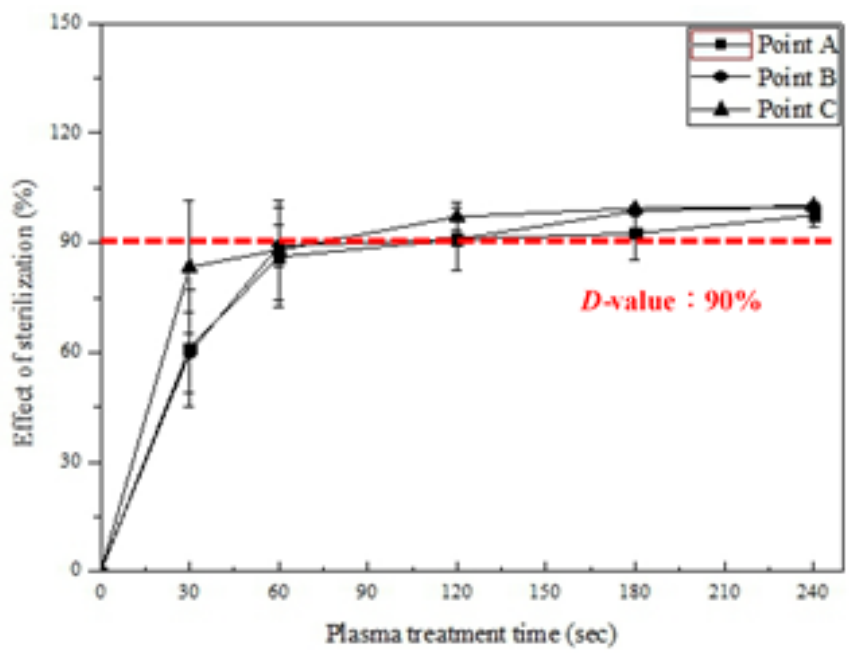

Figure 6. Bactericidal curve

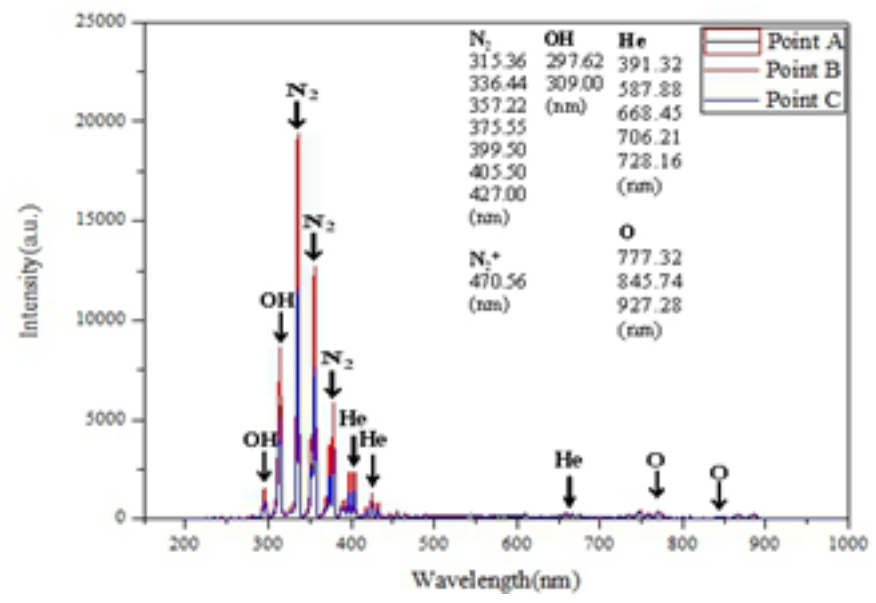

Figure 7. Gas spectra acquired from $200 \mathrm{~nm}$ to $900 \mathrm{~nm}$. 


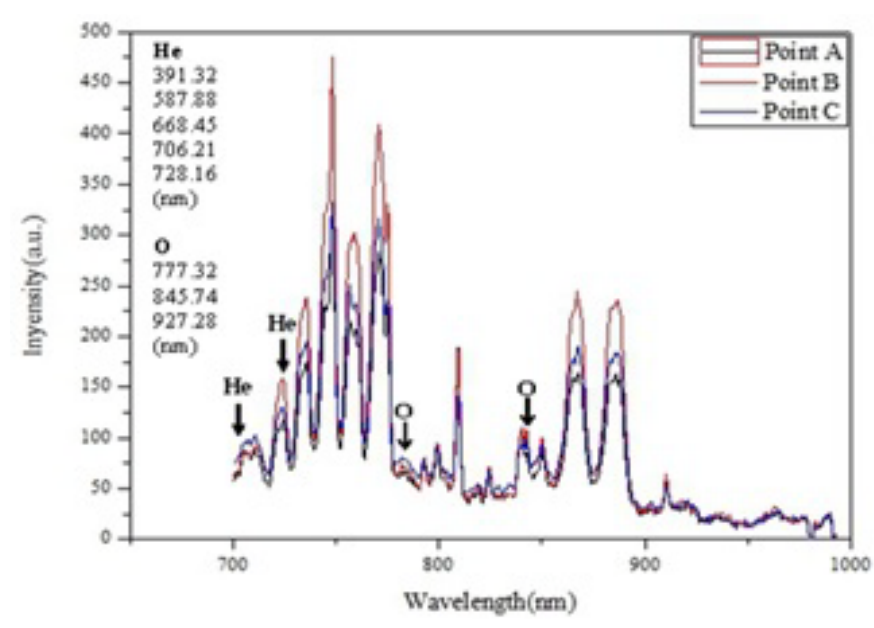

Figure 8. Gas spectra acquired from $700 \mathrm{~nm}$ to $1000 \mathrm{~nm}$.

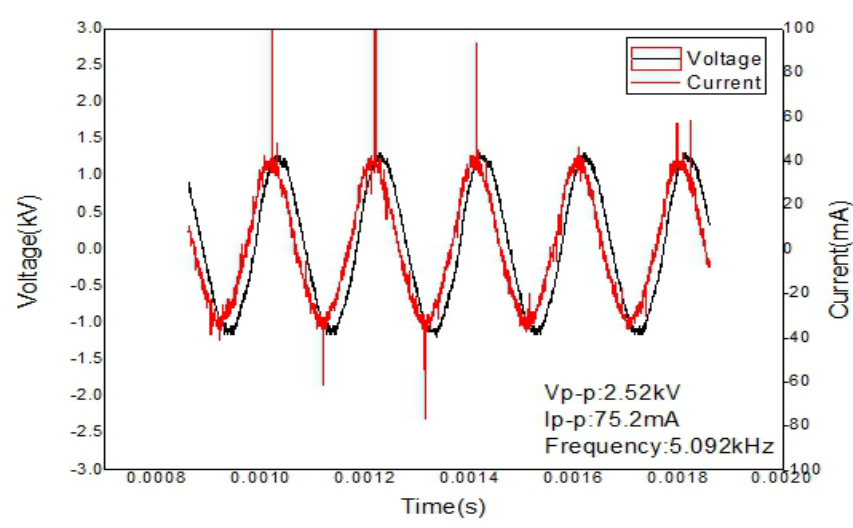

Figure 9. Voltage, current and power waveforms.

The composition of ambient air is $78 \% \mathrm{~N}_{2}$, so it is a common species of atmospheric pressure plasma.

\section{Spectra of $O$}

The spectra are observed at $777.32 \mathrm{~nm}, 845.74 \mathrm{~nm}$ and $927.28 \mathrm{~nm}$.

\section{Spectra of radicals $(\mathrm{OH})$}

The spectra are observed at $297.62 \mathrm{~nm}$ and $309 \mathrm{~nm}$.

Our plasma system can generate reactive oxygen atoms and radicals which were recorded as major species of plasma for sterilization $[6,7]$.

Electrical measurements: Typical voltage, current, and power waveforms and lissajous curve are depicted in Figure 9 and 10 respectively.

The power dissipation is calculated by the product of frequency and the area under the curve.

The examination of thermal of reactor: When the system is worked, plasma is excited while temperature is raised. There was a signpost where the two lines converged as shown in Figure 11. While the plasma was excited, the temperature rose until it stabilized at $53^{\circ} \mathrm{C}$. In the $D$-value, the temperature of the reactor surface is below $50^{\circ} \mathrm{C}$ by $120 \mathrm{~s}$, so the plasma system won't cause thermal stimulation in oral cavity.

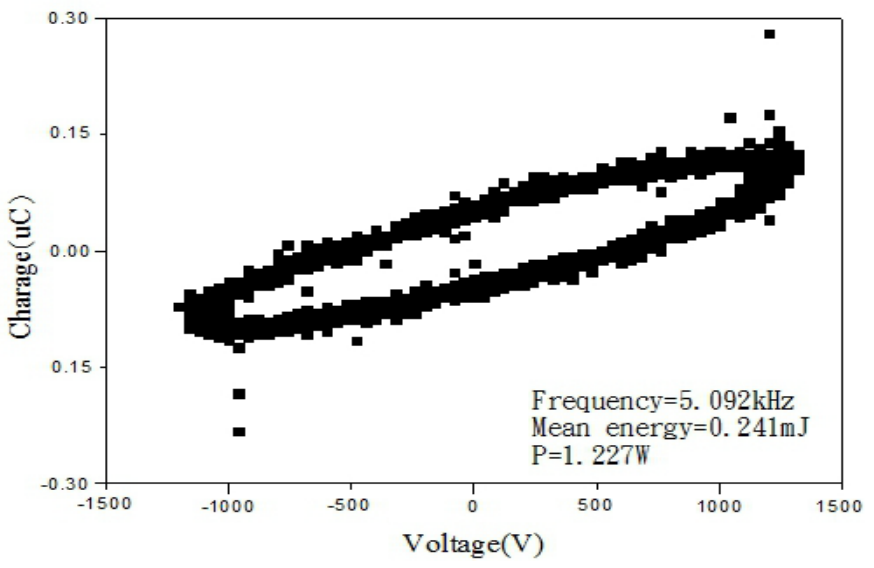

Figure 10. Lissajous curve.

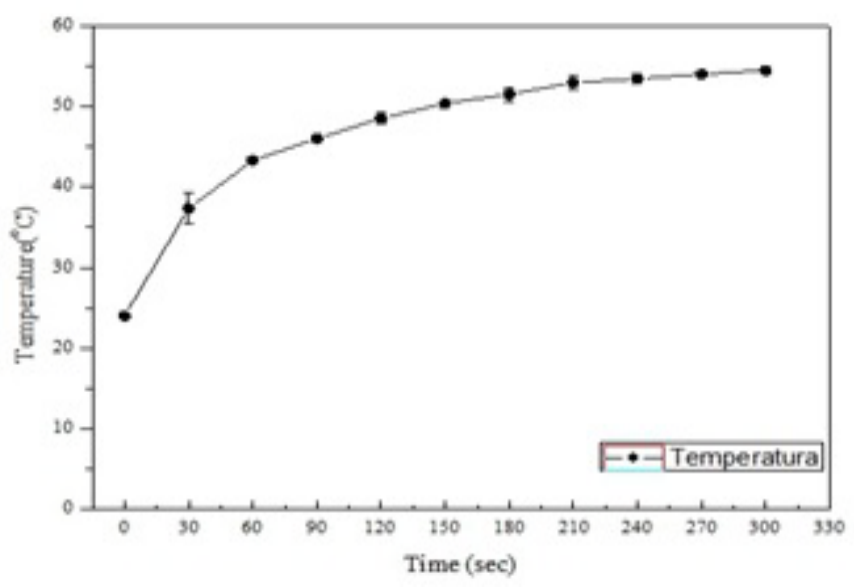

Figure 11. The surface temperature of plasma device.

Table 1. Plasma collision reaction [5].

\begin{tabular}{|c|c|}
\hline ionization & $\begin{array}{l}\mathrm{e}^{-}+\mathrm{M} \rightarrow \mathrm{M}^{+}+2 \mathrm{e}^{-} \\
\mathrm{h} v+\mathrm{M} \rightarrow \mathrm{M}^{+}+\mathrm{e}^{-} \\
\mathrm{M}^{*}+\mathrm{A} \rightarrow \mathrm{M}+\mathrm{A}^{+}+\mathrm{e}^{-}\end{array}$ \\
\hline excitation & $\mathrm{e}^{-}+\mathrm{M} \rightarrow \mathrm{M}^{*} \rightarrow \mathrm{e}^{-}+\mathrm{M}+\mathrm{h} v$ \\
\hline recombination & $\begin{array}{l}\mathrm{M}^{+}+\mathrm{A}^{-} \rightarrow \mathrm{MA} \\
\mathrm{M}^{+}+\mathrm{e}^{-} \rightarrow \mathrm{M} \\
\mathrm{M}^{+}+\mathrm{e}^{-} \rightarrow \mathrm{M}+\mathrm{h} v\end{array}$ \\
\hline dissociation & $\begin{array}{l}\mathrm{e}^{-}+\mathrm{MA} \rightarrow \mathrm{M}+\mathrm{A}+\mathrm{e}^{-} \\
\mathrm{M}^{*}+\mathrm{AB} \rightarrow \mathrm{M}+\mathrm{A}+\mathrm{B} \\
\mathrm{e}^{-}+\mathrm{MA} \rightarrow \mathrm{M}^{+}+\mathrm{A}+2 \mathrm{e}^{-}\end{array}$ \\
\hline charge exchange & $\mathrm{A}^{+}+\mathrm{B} \rightarrow \mathrm{A}+\mathrm{B}^{+}$ \\
\hline elastic scattering & $\begin{array}{l}\mathrm{e}^{-}+\mathrm{M} \rightarrow \mathrm{e}^{-}+\mathrm{M} \\
\mathrm{A}^{+}+\mathrm{B} \rightarrow \mathrm{A}^{+}+\mathrm{B}\end{array}$ \\
\hline chemical reaction & $\mathrm{AB}+\mathrm{C} \rightarrow \mathrm{A}+\mathrm{BC}$ \\
\hline
\end{tabular}

\section{Conclusions}

This study demonstrates a Non-thermal Atmospheric Pressure Plasma System operating in ambient-condition air. According to the bactericidal curve, it is obvious antimicrobial effect is dependent on treatment time by plasma. The bactericidal effects on different places depend on the degree of evenness of the surface. Results show that $90 \%$ inactivation and complete inactivation require about $2 \mathrm{~min}$ and 4 min of plasma operation at three random places, respectively, so the generating plasma from our reactor is even. When the input parameters are $2.52 \mathrm{kV}_{\mathrm{p}-\mathrm{p}}, 5.092 \mathrm{kHz}$, and $1.227 \mathrm{~W}$, detected by OES reveals these 
ROS of plasma which are provided with oxygen stress to bacteria, including $\mathrm{OHO}$ etc.

\section{Acknowledgment}

First, we thank Yu-Ching Teng, Yi-Sheng Wu, Yu-Hsiu Wang and Ming-Kuan Chen for assistance in performing experiments. We also appreciate every member of Lab 815 who gave any support and suggestions.

\section{Conflict of interest}

We have no conflict of interest.

\section{References}

1. Darveau RP (2010) Periodontitis: a polymicrobial disruption of host homeostasis. Nat Rev Microbiol 8: 481-490. [Crossref]

2. Hope CK, Hindley JA, Khan Z, de Jong ED, Higham SM (2016) Lethal photosensitization of Porphyromonas gingivalis by their endogenous porphyrins under anaerobic conditions: An in vitro study. Photodiagnosis and Photodynamic Therapy 10: 677-682.

3. Wilson M (2004) Lethal photosensitisation of oral bacteria and its potential application in the photodynamic therapy of oral infections. Photochemical \& Photobiological Sciences 3: $412-418$

4. Abbas M, Zahra C, Mahvash M, Reza F, Neda M, et al. (2016) Antimicrobial photodynamic therapy using diode laser activated indocyanine green as an adjunct in the treatment of chronic periodontitis: A randomized clinical trial. Photodiagnosis and Photodynamic Therapy 14: 93-97.

5. Eliasson B, Kogelschatz U (1991) Modeling and applications of silent discharge plasmas. IEEE Transactions on Plasma Science 19: 309-323.

6. Jung H, Kim DB, Gweon B, Moon SY, Choe W (2010) Enhanced inactivation of bacterial spores by atmospheric pressure plasma with catalyst TiO2. Applied Catalysis B-Environmental 93: 212-216.

7. Smith Simon A, Anghel SD, Papiu M, Dinu O (2009) Diagnostics and active species formation in an atmospheric pressure helium sterilization plasma source. Nuclear Instruments and Methods in Physics Research Section B: Beam Interactions with Materials and Atoms 267: 438-441.

Copyright: (C2016 Sun SY. This is an open-access article distributed under the terms of the Creative Commons Attribution License, which permits unrestricted use, distribution, and reproduction in any medium, provided the original author and source are credited. 